\title{
Dyslexia: A language learning impairment
}

\author{
Joint British Academy/British Psychological Society Lecture \\ read 24 September 2013 by
}

\section{MARGARET J. SNOWLING \\ Fellow of the Academy}

Abstract: Without the ability to read fluently with comprehension there is a downward spiral of poor educational achievement and career prospects. Dyslexia is therefore a major problem for society and a key question is whether it is possible to intervene early to ameliorate its impact. Studies following the development of children at family-risk of dyslexia reveal that it is associated with language delays and speech difficulties in the pre-school years before reading instruction begins. Literacy outcomes for children depend not only on the risk factors that predispose to reading difficulties but also on protective factors which mitigate the risk. Together current evidence places dyslexia on a continuum with other language learning impairments.

Keywords: Dyslexia, SLI, language learning impairment, reading difficulties, risk studies.

Dyslexia is a life-time persistent disorder which affects the ability to read and spell. According to the new diagnostic manual of the American Psychiatric Association, DSM-5 (American Psychiatric Association, 2013), dyslexia is one of several learning difficulties classified together under the umbrella term 'Specific Learning Disorder'. It might seem reasonable at the outset to ask, 'Why a difficulty that primarily affects the ability to decode print should be classed as a form of mental disorder?' The question is apposite. But, if people with dyslexia are not properly supported, they can face a downward spiral of poor literacy, poor education and limited career prospects, with a negative impact on their adult well-being. Dyslexia is therefore not only a problem for the individual but also for society as a whole.

The first description of dyslexia in Britain was by a general practitioner, Dr Pringle-Morgan in 1896. After this, the causes of the condition, then referred to as 'congenital word blindness', remained the domain of medical specialists for some seventy years. An important study conducted by Rutter \& Yule in 1973 was a turning point in terms of our understanding of this 'hidden' disorder. Rutter \& Yule (1973) used a survey of the entire 9-year-old population of the Isle of Wight to differentiate two kinds of reading problem: children who had reading problems which were out of 
line with expectation given their age but in line with their Mental Age (they called these children 'children with general reading backwardness'); and children whose reading was out of line with expectation based on IQ (calling these, children with 'specific reading retardation'). Two points from this classic study resonate with current knowledge of children's reading difficulties. First, there was no evidence for a discrete condition of 'dyslexia', though the prevalence of specific reading retardation was greater than might be anticipated given just the normal distribution of reading skill. Second, and critically, children with both types of reading difficulty experienced delays and difficulties in language development, these being more circumscribed in the group with specific reading retardation.

At around the same time, researchers in the field of cognitive psychology were beginning to become interested in the process of learning to read and in reading difficulties. In 1979, Vellutino published a landmark text, Dyslexia: Research and Theory, in which he reviewed the large body of research suggesting that dyslexia is due to a perceptual difficulty. Instead, he argued that dyslexia was a verbal coding problem, an idea subsequently recast as the 'phonological deficit hypothesis' (Vellutino et al., 2004). In short, learning to read, regardless of the script, requires the establishment of mappings between the spoken and written language domains. In an alphabetic system like English, these fine-grained mappings are between the letters of printed words, or graphemes, and the sounds of spoken words, the phonemes, and involve access to the phonemes of spoken language. This is no mean feat as many others have stated. Indeed, one might go so far as to say that cracking the alphabetic code is one of the major accomplishments of cognitive development. Furthermore, according to the phonological deficit hypothesis, the proximal cause of dyslexia is a difficulty at the level of speech sounds (phonemes), creating a problem in establishing the mappings - that is, a problem of phonological processing leading to a learning disorder. A growing body of evidence now shows that the phonological deficit in dyslexia may be universal, not only across alphabetic languages (Caravolas et al., 2012), but also in Chinese (McBrideChang et al., 2011) and in the alphasyllabaries of southern India (Nag \& Snowling, 2011).

It is perhaps useful to note at this point that dyslexia is the name given to a set of reading behaviours rather than a distinct category. These behaviours are the outcome of multiple factors, genetic and environmental which, through interaction, lead to a continuous distribution of outcomes with no clear cut-off (Pennington, 2006). Moreover, contrary to the view that dyslexia occurs in people of good cognitive ability, it is now agreed that 'dyslexia' occurs across the range of abilities and that the term can be equally applied to those of lower IQ (Snowling \& Hulme, 2012 for review). It follows that 'diagnosing dyslexia' on the basis of a discrepancy between IQ and reading skill is no longer accepted practice. 
It is argued in this paper that, regardless of the consensus that phonological skills are the prime determinants of learning to read, there is an 'elephant in the room'. The elephant is language. Learning to read builds on a foundation in spoken language skills and children who come to school with poor oral language skills are at high risk of reading difficulties (Bishop \& Snowling, 2004 for a review; Catts et al., 2002). Thus, although the theory that phonological deficits are the proximal cause of dyslexia is robust, an over-emphasis on these deficits does a disservice to those with languagelearning impairments whose phonological skills are not well developed at school entry. The paper begins with a review of what is known about the precursors of dyslexia in the pre-school years, pointing to quite widespread delays and difficulties in speech and language development. It continues with a discussion of the relationship between dyslexia and specific language impairment, before outlining a new causal model of dyslexia and its implications for intervention. Taken together the findings reinforce the importance of language as a vital prerequisite for becoming literate.

\section{PRECURSORS OF DYSLEXIA IN THE LANGUAGE DOMAIN}

For many years, the study of dyslexia proceeded in laboratory-based studies of highly selected clinical groups. Such studies are subject to referral bias and often children with significant difficulties are excluded because of co-occurring issues. Quite a different approach is offered by longitudinal studies which follow the development of children at high risk of dyslexia from the pre-school years, and proceed to examine the characteristics of those who go on to be dyslexic compared to those who are deemed to be 'normal' readers.

The first of these studies was reported by Scarborough (1990). In this study she highlighted the crucial importance of language to literacy development, an issue which had been neglected for some years, arguably because of the dominance of both the 'discrepancy definition' of dyslexia and the phonological deficit theory (e.g. Stanovich 1994). Scarborough found that, in the pre-school years, children with dyslexia exhibited a changing profile of language strengths and difficulties. At 2-3 years old, although they used as many words as children in a control group without a family history of dyslexia, they were less intelligible and also had grammatical difficulties and from 3-5 years old they had difficulties in naming objects. These spoken language impairments presaged difficulties with phonological awareness and in the development of early reading skills. The study suggested that oral language difficulties were a distal cause of reading problems, in line with the earlier findings of the Isle of Wight study. 
Since 1990, several studies of children at family risk of dyslexia have been completed and others are ongoing. The 'standard' paradigm has become to follow children with a first-degree relative who is dyslexic (normally a parent but sometimes an older sibling) alongside peers of the same age from families with no history of reading difficulties. The typical time frame is from pre-school to around Year 3, when the children are assessed and classified into three groups. The first group consists of children at family risk of dyslexia who are 'identified' as dyslexic (FR-dyslexia), the second group is of children at family risk of dyslexia who are deemed to be normal readers (family risk-normal reader; FR-NR) and the third group consists of typically developing (TD) children who, by definition, are at low risk of dyslexia and who do not have reading difficulties (TD-NR). In some but not all studies, a small group of the controls succumb to reading problems, as would be expected (about 10 per cent) and these children are excluded from further attention.

Having classified the children in Year 3, the next step is to conduct a retrospective analysis of group and sub-group differences at early developmental stages to reveal the precursors of reading difficulties (Snowling \& Melby-Lervag, submitted, for a review). Together these studies confirm a heightened prevalence of dyslexia, some 44 per cent, in children at family risk compared to controls. Of course such data carry with them the assumption that dyslexia is a discrete category; as already discussed, this cannot be assumed. Indeed, examining literacy outcomes at the age of around eight, children at family risk who are not defined as dyslexic typically do less well on tests of reading and spelling than their peers. In short, although they do not qualify for the label of dyslexia, they still show some symptoms of reading and spelling disorder.

More importantly for our present argument, we can ask the question 'Do children who go on to be dyslexic experience phonological difficulties in the pre-school years and, if so, are they specific or part and parcel of a broader language delay?' With one or two exceptions, the emerging picture suggests that children who go on to be dyslexic do show significant difficulties with phonological skills; these difficulties include problems repeating novel words (non-word repetition), recalling verbal items in short term memory (which draws on phonological codes) and difficulties with phonological awareness (taking away the sound in a word, for example 'black $\rightarrow$ back') but they also experience broader difficulties with aspects of language comprehension, particularly receptive vocabulary.

Arguably, what is more surprising is that the FR-NR group also show the same broad range of linguistic problems in pre-school, though to a lesser extent. In fact, it is not until school age that the developmental trajectory indicative of slow language development in the two family-risk groups appears to diverge. According to the 
meta-analysis at school age, those with dyslexia continue to experience difficulties in language comprehension and in phonological awareness. In contrast, the FR-NR group appear to resolve their language problems though their phonological awareness remains weak. The finding that both family-risk groups, regardless of whether or not they go on to have significant reading problems, have problems with phonological awareness is important. Contrary to the classic view, it suggests that a phonological deficit alone is not sufficient to cause dyslexia; the likelihood of 'diagnosis' is increased when dyslexia occurs in the context of broader oral language difficulties, or possibly where there are additional co-occurring impairments, for example in attentional processes (Pennington, 2006; Snowling, 2008).

Following on from this, a slightly different way of conceptualising the phonological deficit in dyslexia is in terms of a risk factor, arguably the proximal cognitive cause. But like all risk factors it is probabilistic and can be moderated by additional risk and protective factors. Within a broader biological view in which dyslexia has a hereditary basis (Paracchini et al., 2007), the phonological deficit can be considered as an intermediary between the genes associated with dyslexia and the behavioural disorder. Such an intermediate phenotype is sometimes referred to as a cognitive 'endophenotype' (Moll et al., 2013). Endophenotypes are defined as processes associated with the disorder in the population but expressed at a higher rate in the unaffected relatives of probands than in the general population (Bearden \& Freimer, 2006). Together the family-risk studies suggest that the key issue is how this endophenotype combines with other endophenotypes, as well as protective factors which are present at school entry to determine the course of literacy development.

\section{THE RELATIONSHIP BETWEEN DYSLEXIA AND SPECIFIC LANGUAGE IMPAIRMENT}

If the critical difference between children at family risk of dyslexia who go on to have reading problems and those who do not is the status of the language system at school entry, then this begs the question: what is the relationship between dyslexia and the language disorder known as 'specific language impairment' (SLI) (Bishop, 1997)? Interestingly, a longitudinal study following the outcomes of children with pre-school SLI came to similar conclusions: children whose language difficulties had resolved by $5 \frac{1}{2}$ years, went on to have normal literacy skills at $8 \frac{1}{2}$ (Bishop \& Adams, 1990) and subsequently at school-leaving age (Stothard et al., 1998). However, it is noteworthy that, at the later date, they were found to have some underlying weaknesses in phonological skills; these included poor performance on a test of Spoonerisms, a challenging 
task tapping phoneme awareness in which initial sounds of two words have to be exchanged (for example 'Phil Collins $\rightarrow$ Kill Follins') and poor non-word repetition relative to age and ability-matched controls.

Building on these findings, Bishop \& Snowling (2004) reviewed the extant literature on the relationship between dyslexia and SLI, which is large and somewhat inconsistent in its findings. They proposed this inconsistency arises because the relationship between the two disorders is not a simple one, and two different dimensions need to be taken into account to specify it. The first dimension comprises the phonological skills that underpin the development of decoding (and the alphabetic principle), the second, the grammatical, syntactic and semantic skills that are critical for reading comprehension. Within this framework, dyslexia and SLI share deficits in phonological skills but differ with regard to broader oral language skills. There are continuities between the disorders since each of the 'dimensions' varies from impaired to superior. Broadly speaking, a similar view has emerged from two subsequent studies. On the basis of a large population study, Catts et al. (2005) concluded that dyslexia and SLI can be viewed as co-occurring conditions, the co-morbidity accounted for by shared phonological deficits (though bearing in mind that some children with SLI do not experience phonological difficulties, Nation et al., 2004, and form a different subgroup). Similarly, Ramus et al. (2013) argued that SLI and dyslexia share deficits in phonological skills but also proposed that the profile of the two disorders is different. While SLI is associated with deficits at the level of phonological representations as well as in phonological skills, they proposed that dyslexia is primarily a deficit in the skills that operate on phonological representations and not the representations themselves.

More recently, we have been following the development from pre-school through to the age of eight, of children with a family risk of dyslexia, children with preschool specific language impairment and controls. The research question driving this project is the developmental continuities between the two disorders and the shared risk factors. A key hypothesis is that phonological deficits represent a shared endophenotype between dyslexia and SLI; however, a further prediction is that the two disorders will differ in terms of co-morbidities, increasing the probability of diagnosis.

Recruitment to our study was a three-stage process. Following a call for volunteers of parents with pre-school children either at family risk of dyslexia, language impaired or typically developing, the parents (regardless of parental self-report) underwent objective assessment to determine their literacy status (Snowling et al., 2012). This process led to classification of the families and their children into two groups: at family risk or not at risk. Next, following a language assessment, the children were grouped 
as to whether they fulfilled research criteria for language impairment. We defined language impairment as falling more than one standard deviation below the mean on two out of four measures of receptive and expressive language skills.

Our recruitment procedure yielded four groups of children: the first group were typically developing, the second, a group of children who had language impairment, third a group of children who were at family risk of dyslexia but without language impairment, and finally a group at family risk of dyslexia and who also had language impairment. A novel finding was that, amongst children at family risk of dyslexia, about a third appear to have language difficulties which are sufficient at $3 \frac{1}{2}$ years for them to be considered as having a pre-school language impairment (Nash et al., 2013).

Our first question then was: are there differences between children who are language impaired and also at family risk of dyslexia and children with language impairments without family risk? The answer was 'No' - both groups showed broad deficits in oral language skills including poor phonology in pre-school and there was no significant difference between them; hence for present purposes, we can regard these two group as similar.

Turning now to children at family risk of dyslexia without SLI (FR-only), these children were found to have difficulties on phonological tasks that tapped speech production, namely articulation, word and non-word repetition. They were also impaired in the production of grammatical inflections, that is, with the endings of verbs (past tense $-e d$; third person singular $-s$ ) and in repeating sentences, particularly the function words within them. All of these tasks require access to phonological codes. The FR-only group also showed emerging difficulties with phonological awareness in an alliteration matching task.

Together, this pattern of deficit highlights the fact that poor phonological language is a risk factor for dyslexia, prevalent among children at family risk. The pattern was consistent across the first two phases of the study, though some of the grammatical impairments were beginning to resolve by the time children were $4 \frac{1}{2}$ years old (Nash et al., 2013 for further details). Moreover, 44 per cent of the family risk sample had a significant non-word repetition deficit, commonly considered as a behavioural marker of SLI. This finding underlines the continuity between dyslexia and SLI. More generally our data are consistent with the hypothesis of a phonological endophenotype associated with dyslexia, with the differences between dyslexia and SLI hinging on additional co-occurring risk factors. For example, Gooch et al. (2014) showed that the children in the SLI groups are far more likely to have difficulties with executive attention and motor development than children at family risk without language impairment. 


\section{ENVIRONMENTAL INFLUENCES ON DYSLEXIA}

Can these sorts of data be used to move toward a causal model of dyslexia? So far, rather little has been said about the etiology of dyslexia and the distal risk factors. Dyslexia is usually considered to be best characterised as a neurodevelopmental disorder, meaning that it is evident from early in development and has biological origins; furthermore, as is typical of most such disorders, there is a preponderance in males (Thapar \& Rutter, in press). The ultimate cause of dyslexia is thought to be genetic and some candidate genes have been identified (Paracchini et al., 2007). However, environmental variables also play a critical role.

Thus, it seems appropriate to choose a framework which could be applied to a range of neurodevelopmental disorders, including, for example, ADHD and autism; in all of these conditions, several risk factors act together through the environment to produce the behavioural phenotype of the disorder. The more risk factors that are present, the greater the likelihood of the disorder being diagnosed. It follows that clinical samples tend to be impure in the sense that there is more likely to be a referral leading to a diagnosis in children with multiple risk factors.

In relation to dyslexia it is likely that at least three aspects of the environment are important: the language of instruction, the home literacy environment and the teaching the child has received.

First, not all written languages are equally easy to learn to read. Alphabetic languages differ in the regularity or consistency with which the letters and sounds in them are related, as well as in their syllabic complexity. Both of these factors determine the rate of reading acquisition in a given language (Caravolas et al., 2013; Seymour, 2005). For example, a child learning to read in the highly consistent Finnish language will on average do so much more quickly than a child learning in English. Nevertheless, a striking finding is that the predictors of individual differences in reading attainment across these languages are similar and include letter knowledge, phoneme awareness and performance on a test requiring the rapid naming of symbols or objects (rapid automatised naming, RAN) (Caravolas et al., 2012). What this means is, if you have the genes which confer risk for dyslexia, you will have difficulties learning to read in any language, although the actual rate and extent of the difficulty might vary (Frith et al., 1998).

Turning to the environment in the home, research on typical development suggests that in terms of home literacy, parenting styles differ and these differences affect reading development. Some parents provide fairly direct instruction about print concepts, letters and sounds when reading with their pre-school child and this practice appears to be a good predictor of early decoding skill. In contrast, some parents place an emphasis on oral language during shared-book reading, talking about the pictures, the characters and the story. This kind of language experience approach is more 
strongly predictive of individual differences in reading comprehension at a later stage in development than of decoding (Sénéchal \& Lefevre, 2002). Turning to dyslexia, relatively few studies of home literacy environment have specifically focused on children at family risk. However, there is no strong evidence to date that children at family risk of dyslexia experience any different kind of literacy environment from controls of similar socio-economic status, though print motivation may be lower in older children who have actually developed dyslexia (Snowling et al., 2007). In our own work we have shown that among children at family risk of dyslexia as for controls, shared reading mediates the impact of the mother's educational level on language and reading development (Hamilton, 2013). We have also looked at the predictors of preschool letter knowledge in these groups because this is a measure which is thought to be highly dependent on environmental input; an interesting finding is that parental teaching of letters and sounds accounts for more variability in the family-risk group than in the low risk typically developing group. This finding is important - it suggests that typically developing children can learn the sounds of letters quite naturally from their environment, whereas children at family risk of dyslexia need more explicit teaching in order to do so.

\section{WHAT WORKS FOR DYSLEXIA?}

The starting point for an intervention should be a causal model. Based on the evidence discussed here and elsewhere, both from studies of typical reading development and of dyslexia, we can state confidently that learning to read requires phonological awareness and a primary risk factor for dyslexia is a phonological deficit. Moreover, we have seen that phonological deficits in dyslexia are prevalent in children at family risk of the condition even before reading instruction begins. But we also know from the study of Nash et al. (2013) that in about a third of cases these children have a language impairment. It follows that interventions for dyslexia need to remediate not only the phonological difficulties at the core of the disorder but also in some cases, residual or co-occurring language difficulties.

The main ingredients of a teaching approach to remediate the decoding deficit in dyslexia combine training in phoneme awareness with training in letter-sound knowledge and in which these two skills are reinforced in the context of reading. Hatcher et al. (1994) were the first group of researchers in the UK to assess the efficacy of such an approach using a controlled design. Children participating in this study were identified through a county-wide screening of all 71/2-year-old children. The children were then provided with one of three types of intervention, and a fourth control group received the usual diet of remediation used at the time in the local education authority. 
The three interventions that were evaluated consisted of: Reading alone (R) in which children read from texts which were selected to be at the appropriate level and teachers reinforced effective reading strategies to hone the children's skills; Phonology alone $(\mathrm{P})$ which consisted of exercises training the development of oral phonological awareness at syllable, rhyme and phoneme levels; and Reading with Phonology $(\mathrm{R}+\mathrm{P})$ which combined the reading and phonology approaches and children were encouraged to practice their emergent skills through reading and writing activities. At the end of the 20 weeks of intervention, the children who received the combined programme $(\mathrm{R}+\mathrm{P})$ were significantly ahead of the other three groups in reading accuracy, spelling and reading comprehension and the gains in reading were maintained five months after the intervention ceased. Following on from this work, the programme was adapted for delivery by trained teaching assistants to children in Year 1 with dyslexic-like difficulties (Hatcher et al., 2006). The programme yielded significant gains in reading accuracy scores on a standardised test of over 7 standard score points during the 20 weeks of the intervention. This rate of improvement can be regarded as educationally significant and an important first step for a child having difficulties with the acquisition of basic reading skills (Brooks, 2013).

But why wait for failure? As we have seen, a great deal is known about what places a child at risk of reading difficulties and therefore there would seem to be no good reason to wait until the child has failed before implementing intervention. With this in mind, Bowyer-Crane et al. (2008) evaluated a 20-week intervention programme using the principles of the $\mathrm{R}+\mathrm{P}$ intervention for children who entered school at risk of reading failure. The programme was a modification of that used by Hatcher et al. (2006), suitable for younger children. It comprised three main components: letter-sound work, segmenting and blending, reading together and reading independently, and alternated between group and individual sessions on a daily basis. Four children worked together in a group on letter-sound knowledge, segmenting and blending, and in the individual sessions the work focused on reading, incorporating time to reinforce work on letters and sounds.

To evaluate the efficacy of this phonologically based programme, the gains of the children on tests of reading and reading-related skills were compared to those of a treated control group who received oral language work. The children who had received the intervention were significantly ahead of the controls in phoneme awareness, prose-reading accuracy, non-word reading and spelling. Moreover, comparison of the outcomes of these children in relation to a large sample of 700 classroom peers five months after the intervention was pleasing, with more than 50 per cent now performing within the average range for early word reading skills (and 7 per cent had standard reading scores above 115). 
In summary, phonologically based reading intervention delivered by trained teaching assistants can be used to boost the foundations of decoding skill and to bring about improvements in reading in children with dyslexia. But there is a problem: if one of the important risk factors for dyslexia is language, then it is perhaps important to think about first of all intervening at the level of oral language as a foundation for phonological awareness. Second, the ultimate goal for literacy is to read fluently with understanding; unless we address the oral language weaknesses of children at risk of reading problems we will only ever find the imperfect solution to the remediation of dyslexia.

\section{LANGUAGE INTERVENTION}

To test the idea that oral language work can provide a strong foundation for learning to read, Fricke et al. (2013) conducted a study in which pre-school children with poorly developed language skills at 4 years old were randomly assigned either to receive a 30-week oral language programme or to a waiting control group who received 'business as usual'. The 30-week programme comprised three main components which ran throughout the sessions: work on oral narrative, vocabulary and listening skills. In nursery school, the activities were delivered to groups of two to four children, three times a week. In Reception class, the components of the programme remained the same but the intensity was increased to three 30-minute sessions a week and two 15-minute individual sessions in which narrative skills were honed; in addition, in the final ten weeks, the sessions were supplemented with work on letter-sound knowledge and phonological awareness. The interventions were delivered by trained and supported teaching assistants in early years' settings.

At the end of the intervention, the group who had received the intervention showed improvements in a broad range of oral language skills including vocabulary, narrative and listening comprehension as well as in expressive (but not receptive) grammar. There was also an impact on their emergent literacy skills namely letter knowledge, alliteration matching and phonetic spelling ability. Although there was no significant impact on reading per se, it needs to be borne in mind that the control group at that time had been receiving instruction in systematic phonics in the mainstream classroom. Some six months later the children who had received the invention were still ahead of their peers in the waiting control group in oral language, narrative skills and phonological awareness. But more importantly, at this stage they were also ahead of them in reading comprehension, an effect entirely attributable to their gains in spoken language skills (and not mediated by word-level decoding abilities). 


\section{TOWARDS A CAUSAL MODEL OF DYSLEXIA}

Together, the large body of empirical research on dyslexia (Vellutino et al., 2004) and more recent findings flowing from longitudinal studies of children at family risk of dyslexia, make a compelling case for viewing dyslexia as a language-learning impairment. A strong hypothesis is that it is a 'sub-type' of specific language impairment (SLI). To draw together the main issues, it seems likely that there are (at least) two separable causes of reading problems in children with language learning impairments: poor phonology and poor language. However, the shared liability between the circumscribed reading problems in 'dyslexia' and the broader spoken and written language problems associated with SLI is attributable to common risk factors in the domain of phonological skills. It can be hypothesised from the evidence reviewed that the trajectories of dyslexia and SLI diverge because the phonological deficit combines with other risk factors to lead to a more pervasive impairment in the SLI. Using evidence from twin studies, Bishop (2006) suggested that a problem with grammar (indexed by difficulties in morpheme generation) needs to be present alongside phonological problems (indexed by poor non-word repetition) for SLI to be diagnosed; interestingly, in the same study, poor non-word repetition was found to be a heritable marker of resolved language delay. There are synergies here with the current evidence from longitudinal studies in which children at family risk of dyslexia who do not succumb to reading problems appear to resolve their spoken language difficulties around the time of school entry. Similarly, we have shown that children with SLI often experience co-morbid difficulties in motor skills and executive attention (Gooch et al., 2014).

The present evidence highlights the fact that phonological difficulties are circumscribed in children at family risk of dyslexia unless they have a concomitant language impairment that is persistent. Together then we can put forward a strong hypothesis. First, as others have proposed (e.g. Chiat, 2001; Baddeley et al., 1998), the phonological deficit is the cause of language-learning difficulties. However, if the mechanisms involved in language learning are unimpaired (as we can infer they are in children whose early language delays resolve), then the phonological deficit will only affect written language skills. In essence, this hypothesis resonates with that of Scarborough \& Dobrich (1990) who proposed the concept of 'illusory recovery' to describe children with language delay whose language difficulties apparently resolved, but who then went on to have reading problems. An alternative hypothesis is, not that the differences between dyslexia and SLI turn on the presence of additional risk and protective factors but rather, as proposed by Ramus et al. (2013), children with SLI have difficulties at the level of phonological representations which cause pervasive language problems, while children with dyslexia have difficulty in accessing these representa- 
tions. Such access is critical to the formation of mappings between phonology and orthography that characterises learning to read.

\section{CONCLUSIONS}

Whilst the theoretical issues surrounding dyslexia and related language-learning impairments will continue to be debated, there is unequivocal evidence that a phonological deficit is the primary risk factor for dyslexia and that co-occurring language difficulties increase the probability of reading difficulties. Moreover, if we define dyslexia as a problem with the development of basic reading and writing fluency, then it is best regarded as the outcome of multiple risk factors and more likely to be identified when more than one deficit is present. This is not to say 'specific' dyslexia cannot occur and the fact that it does so in people of high ability with no other apparent behavioural difficulties is a testament to this.

The message is clear: poor oral language is a major risk factor for poor literacy. Risk factors accumulate towards the threshold for identification of dyslexia and the status of the language system at school entry is a good prognostic indicator. And, as far as we know, phonological aspects of language appear to be universally affected in dyslexia, but diagnosis remains difficult and the cut-off depends on agreed external criteria. On a positive note, we know from intervention research that the impact of phonological risk factors can be ameliorated, thereby preventing a downward spiral of poor educational achievement, disengagement and limited career prospects. To conclude, there needs to be a greater awareness of language as a barrier to learning (Bishop et al., 2012) and the policy agenda needs to shift from a preoccupation with literacy standards towards a greater emphasis on oracy in the early years of education. Written language has its foundations in oral language: ensuring that all children are fluent users of the language of reading instruction is a vital ingredient of successful education.

Acknowledgements: The work described in this article was funded by grants from the Wellcome Trust and the Nuffield Foundation.

\section{REFERENCES}

American Psychiatric Association (2013), Diagnostic and statistical manual of mental disorders (5th edn) (Arlington, VA, American Psychiatric Association).

Baddeley, A., Gathercole, S. \& Papagno, C. (1998), 'The phonological loop as a language learning device', Psychological Review, 105: 158-73. doi: 10.1037/0033-295X.105.1.158 
Bearden, C.E. \& Freimer, N.B. (2006), 'Endophenotypes for psychiatric disorders: ready for primetime?', Trends in Genetics, 22: 306-13. doi: 10.1016/j.tig.2006.04.004

Bishop, D.V.M. (1997), Uncommon Understanding (Hove, Psychology Press).

Bishop, D.V.M. (2006), 'Developmental cognitive genetics: How psychology can inform genetics and vice versa', Quarterly Journal of Experimental Psychology, 59(7): 1153-68. doi: $10.1080 / 17470210500489372$

Bishop, D.V.M. \& Adams, C. (1990), 'A prospective study of the relationship between specific language impairment, phonological disorders and reading retardation', Journal of Child Psychology and Psychiatry, 31: 1027-50. doi: 0.1111/j.1469-7610.1990.tb00844.x

Bishop, D.V.M. \& Snowling, M.J. (2004), 'Developmental dyslexia and specific language impairment: Same or different?', Psychological Bulletin, 130: 858-88. doi 10.1037/0033-2909.130.6.858

Bishop, D.V.M., Clark, B., Conti-Ramsden, G., Norbury, C.F. \& Snowling, M.J. (2012), 'RALLI: An internet campaign for raising awareness of language learning impairments', Child Language, Teaching \& Therapy, 28: 259-62 doi: 10.1177/0265659012459467

Bowyer-Crane, C., Snowling, M.J., Duff, F., Carroll, J., Fieldsend, E., Miles, J., et al. (2008), 'Improving early language and literacy skills: differential effects of an oral language versus a phonology with reading intervention', Journal of Child Psychology and Psychiatry and Allied Disciplines, 49: 422-32. doi: 10.1111/j.1469-7610.2007.01849.x

Brooks, G. (2013), 'What works for children and young people with literacy difficulties: the effectiveness of intervention schemes', retrieved from http://www.interventionsforliteracy.org.uk/ (November 2013).

Caravolas, M., Lervåg, A., Defior, S., Seidlová Málková, G. \& Hulme, C. (2013), 'Different patterns, but equivalent predictors, of growth in reading in consistent and inconsistent orthographies', Psychological Science, 24(8): 1398-1407. doi: 10.1177/0956797612473122

Caravolas, M., Lervåg, A., Mousikou, P., Efrim, C., Litavsky, M., Onochie-Quintanilla, E., et al. (2012), 'Common patterns of prediction of literacy development in different alphabetic orthographies', Psychological Science, 23(6): 678-86. doi: 10.1177/0956797611434536

Catts, H.W., Adlof, S.M., Hogan, T.P. \& Ellis Weismer, S. (2005), 'Are specific language impairment and dyslexia distinct disorders?', Journal of Speech, Hearing and Language Research, 48: 1378-96. doi:10.1044/1092-4388(2005/096)

Catts, H.W., Fey, M.E., Tomblin, J.B. \& Zhang, X. (2002), 'A longitudinal investigation of reading outcomes in children with language impairments', Journal of Speech, Hearing \& Language Research, 45: 1142-57. doi: 10.1044/1092-4388(2002/093)

Chiat, S. (2001), 'Mapping theories of developmental language impairment: premises, predictions and evidence', Language and Cognitive Processes, 16: 113-42. doi: 10.1080/01690960042000012

Fricke, S., Bowyer-Crane, C., Haley, A.J., Hulme, C. \& Snowling, M.J. (2013), 'Efficacy of language intervention in the early years', Journal of Child Psychology and Psychiatry, 54(3): 280-90. doi: 10.1111 jcpp. 12010

Frith, U., Wimmer, H. \& Landerl, K. (1998), 'Differences in phonological recoding in German and English speaking children', Scientific Studies of Reading, 2(1): 31-54. doi: 10.1207/s1532799xssr0201_2

Gooch, D., Nash, H., Hulme, C. \& Snowling, M. (2014), 'Comorbidities in preschool children at family risk of dyslexia', Journal of Child Psychology and Psychiatry, 55(3): 237-46. doi: 10.1111/jcpp.12139

Hamilton, L. (2013), The role of the Home Literacy Environment in the early literacy development of children at family-risk of dyslexia, Ph.D. thesis, University of York.

Hatcher, P., Hulme, C. \& Ellis, A.W. (1994), 'Ameliorating early reading failure by integrating the teaching of reading and phonological skills: The phonological linkage hypothesis', Child Development, 65: 41-57. doi 10.2307/1131364 
Hatcher, P.J., Hulme, C., Miles, J.N.V., Carroll, J.M., Hatcher, J., Gibbs, S., Smith, G., Bowyer-Crane, C. \& Snowling, M.J. (2006), 'Efficacy of small group reading intervention for beginning readers with reading-delay: a randomised controlled trial', Journal of Child Psychology and Psychiatry, 47(8): 820-27. doi: 10.1111/j.1469-7610.2005.01559.x

Moll, K., Loff, A. \& Snowling, M. (2013), 'Cognitive endophenotypes of dyslexia', Scientific Studies of Reading, 2013: 1-13. doi: 10.1080/10888438.2012.736439

McBride-Chang, C., Lam, F., Lam, C., Chan, B., Fong, C.Y.C., Wong, T.T.Y., et al. (2011), 'Early predictors of dyslexia in Chinese children: familial history of dyslexia, language delay, and cognitive profiles', Journal of Child Psychology and Psychiatry, 52(2): 204-11. doi: 10.1111/j.1469-7610.2010.02299.x

Nag, S. \& Snowling, M.J. (2011), 'Cognitive profiles of poor readers of Kannada', Reading and Writing: An Interdisciplinary Journal, 24(6): 657-76. doi: 10.1007/s11145-010-9258-7

Nash, H., Gooch, D., Hulme, C. \& Snowling, M. (2013), 'Preschool Language Profiles of Children at Family Risk of Dyslexia: Continuities with SLI', Journal of Child Psychology and Psychiatry and Allied Disciplines, 54(9): 958-68. doi: 10.1111/jcpp.12091

Nation, K., Clarke, P., Marshall, C. \& Durand, M. (2004), 'Hidden language impairments in children: parallels between poor reading comprehension and specific language impairment?', Journal of Speech, Language \& Hearing Research, 47: 199-211. doi: 10.1044/1092-4388(2004/017)

Paracchini, S., Scerri, T. \& Monaco, A.P. (2007), 'The genetic lexicon of dyslexia', Annual Review of Genomics \& Human Genetics, 8: 57-79. doi: 10.1146/annurev.genom.8.080706.092312

Pennington, B.F. (2006), 'From single to multiple deficit models of developmental disorders', Cognition, 101: 385-413. doi: 10.1016/j.cognition.2006.04.008

Ramus, F., Marshall, C.R., Rosen, S. \& van der Lely, H.K.J. (2013), 'Phonological deficits in specific language impairment and developmental dyslexia: towards a multidimensional model', Brain, 136(2): 630-45. doi: 10.1093/brain/aws356

Rutter, M. \& Yule, W. (1973), 'Specific reading retardation', in L. Mann \& D. Sabatino (eds.), The First Review of Special Education (Philadelphia, Buttonwood Farms), 49-62.

Scarborough, H.S. (1990), 'Very early language deficits in dyslexic children', Child Development, 61: 1728-43. doi: 10.1111/j.1467-8624.1990.tb03562.x

Scarborough, H.S. \& Dobrich, W. (1990), 'Development of children with early language delays', Journal of Speech and Hearing Research, 33: 70-83. doi: 10.1044/jshr.3301.70

Sénéchal, M. \& LeFevre, J. (2002), 'Parental involvement in the development of children's reading skill: a five-year longitudinal study', Child Development, 73(2), 445-60. doi: 10.1111/1467-8624.00417

Seymour, P.H.K. (2005), 'Early reading development in European orthographies', in M.J. Snowling \& C. Hulme (eds.), The Science of reading: A Handbook (Oxford, Blackwell), 296-315.

Snowling, M.J. (2008), 'Specific disorders and broader phenotypes: the case of dyslexia', Quarterly Journal of Experimental Psychology, 61, 142-56. doi: 10.1080/17470210701508830

Snowling, M.J. \& Hulme, C. (2012), 'Interventions for children's language and literacy difficulties', International Journal Language \& Communication Disorders, 47(1): 27-34. doi: 10.1111/ j.1460-6984.2011.00081.x

Snowling, M.J. \& Melby-Lervag, M. (submitted), 'Children at family risk of dyslexia: a review and meta-analysis'.

Snowling, M.J., Muter, V. \& Carroll, J.M. (2007), 'Children at family risk of dyslexia: a follow-up in adolescence', Journal of Child Psychology \& Psychiatry, 48: 609-18. doi: 10.1111/j.1469-7610.2006.01725.x

Snowling, M. J., Dawes, P., Nash, H. \& Hulme, C. (2012), 'Validity of a Protocol for Adult Self-Report of Dyslexia and Related Difficulties', Dyslexia, 18: 1-15. doi: 10.1002/dys.1432

Stanovich, K.E. (1994), 'Does dyslexia exist?', Journal of Child Psychology and Psychiatry, 35(4): 579-95. doi: 10.1111/j.1469-7610.1994.tb01208.x 
Stothard, S.E., Snowling, M.J., Bishop, D.V.M., Chipchase, B. \& Kaplan, C. (1998), 'Language impaired pre-schoolers: A follow-up in adolescence', Journal of Speech, Language and Hearing Research, 41: 407-18.

Thapar, A. \& Rutter, M. (in press), 'Neurodevelopment and Neurodevelopmental Disorders: Conceptual Issues', in A. Thapar, D. Pine, J. Leckman, S. Scott, M. Snowling \& E. Taylor (eds.), Rutter's Child and Adolescent Psychiatry, 6th edn (London, Wiley), forthcoming.

Vellutino, F.R. (1979), Dyslexia: Research and Theory (Cambridge, MA, MIT Press).

Vellutino, F.R., Fletcher, J.M., Snowling, M.J. \& Scanlon, D.M. (2004), 'Specific reading disability (dyslexia): what have we learned in the past four decades?', Journal of Child Psychology \& Psychiatry, 45(1): 2-40. doi: 10.1046/j.0021-9630.2003.00305.

Note on the author: Maggie Snowling, FBA, FMed Sci, is Professor in the Department of Experimental Psychology, University of Oxford and President of St John's College. Her research focuses on children's language and learning and she is specifically interested in the nature and causes of children's reading difficulties and how best to ameliorate them. She is also a qualified clinical psychologist. She served as a member of Sir Jim Rose's Expert Advisory Group on provision for Dyslexia in 2009 and as an expert member of the Education for All: Fast Track Initiative group in Washington DC in 2011. Recent publications include:

Clarke, P.J., Truelove, E., Hulme, C. \& Snowling, M.J. (2013), Developing Reading Comprehension (Oxford, Wiley-Blackwell).

Fricke, S., Bowyer-Crane, C., Haley, A., Hulme, C. \& Snowling, M.J. (2013), 'Building a secure foundation for literacy: An evaluation of a preschool language intervention', Journal of Child Psychology \& Psychiatry, 54(3): 280-90. doi: 10.1111/jcpp.12010

Nash, H.M, Hulme, C., Gooch, D. \& Snowling, M.J. (2013), 'Preschool Language Profiles of Children at Family Risk of Dyslexia: Continuities with SLI', Journal of Child Psychology \& Psychiatry, 54(9): 958-68. doi: 10.1111/jcpp.12091

Henderson, L., Clarke, P. \& Snowling, M.J. (2011), 'Accessing and selecting word meaning in autism spectrum disorder', Journal of Child Psychology \& Psychiatry, 52(9): 964-73 DOI: 10.1111/j.1469-7610.2011.02393.x

Contact: maggie.snowling@sjc.ox.ac.uk

This article is licensed under a

Creative Commons Attribution-NonCommercial-NoDerivs 3.0 Unported License.

Journal of the British Academy (ISSN 2052-7217) is published by

The British Academy - the national academy for the humanities and social sciences.

10-11 Carlton House Terrace, London, SW1Y 5AH

www.britishacademy.ac.uk 